\title{
Interior Glazing Systems: market analysis
}

\author{
Ryan E. Smith ${ }^{1 *}$ and Joshua Workman ${ }^{2}$ \\ ${ }^{1}$ Associate Professor, School of Architecture, University of Utah \\ ${ }^{2}$ Research Associate, School of Architecture, University of Utah \\ *Corresponding author's e-mail: rsmith@arch.utah.edu
}

\begin{abstract}
This research represents a three-phase study concerning interior glazing systems. Through data obtained via surveys and interviews, this research suggests how a manufacturing/supply company might enter the interior glazing system market successfully. The research explores the conditions which affect a designer's decision to specify a particular glazing system, creating a database of the criteria by which IGS is selected. The research concludes by offering suggestions which will help a company know which types of products are most often used, the types of buildings that should be targeted as primary markets, the most important qualities of the glass products they intend to manufacture, and how to go about educating designers about their products in a way that will help them be more often selected for construction projects.
\end{abstract}

\section{KEYWORDS}

Interior Glazing System (IGS), Prefabricated Interiors, Market Assessment

\section{INTRODUCTION}

The use of interior glazing systems (IGS) in buildings is steadily on the rise demonstrated by the increase in revenues for IGS companies and the number of such companies also increasing. Furthermore, there are a surprising number of patents filed on interior glazed partition systems in a patent search.' Jochen Grönegräs, of the German Federal Association of Flat Glass Manufacturers has stated, "Interior applications are increasingly significant for the glass market. Our figures say that approximately half the total quantity of single-pane safety glass sold in Germany and almost a quarter of all laminated safety glass is used for interiors."

Justin Burkhart, Project Manager for Key Glass states, "We did a project recently, point-support all-glass elevator enclosure. Interior handrails. Architects are demanding more glass for the interior." "iii Chris Hanstad, V.P. of Architectural Sales for C.R. Laurence, confirms this. "More and more, people want heavy glass - they want the frameless heavy glass look on the interior. They don't want frames - they want less metal. They want something that will give them unobstructed views, something that doesn't create walls."2 CRL Lawrence, an IGS fittings company, has been acquired by exterior curtain wall manufacturer Oldcastle Building Envelope.

Aside from looking clean, sleek, and cutting edge, interior glass helps natural light penetrate further into a building than is possible with framed partition walls. IGS is not only used in office 
environments, but also more recently in schools where visual transparency is being required in remodels and new builds in order to foster increased collaboration and safety.iv Glass interiors have psychological and social impacts on the aesthetics, community and privacy that blurs the boundaries between public and private domains in buildings. ${ }^{\vee}$ However, IGS is much more expensive than other interior space delineating solutions such as frame and gypsum board partition walls.

This research study attempts to answer questions surrounding the use of interior glazing systems in construction projects, focusing primarily on glass partition systems including:

- Why do designers specify glass, rather than lower cost, traditional alternatives to demising space?

- Where do designers obtain information in order to specify glass?

- Although there are suppliers who provide similar products, how can a new supplier enter the market and stand out from the competition?

- What types of products can be developed that offer improved performance compared to existing products?

- Among project stakeholders, who has the greatest influence on which products are ultimately selected for use in a project?

\section{METHOD}

The research included three phases:

Phase 1 Archival - Account for the products currently offered by suppliers of interior glazing systems;

Phase 2 Quantitative - Conduct a questionnaire to licensed architects and interior designers across North America; and

Phase 3 Qualitative - Interview professionals involved in four discrete IGS case studies projects completed nationally to understand how the glazing systems were selected and why.

\section{Phase 1 - Archival}

The first phase of the research project represents a high-level view of the products offered by IGS manufacturers and suppliers. The intent of this exercise was to create a database of the products being offered by IGS companies in the industry in order to compare offerings based on their basic specifications and qualities. A list of 19 of the largest IGS suppliers across the globe was created and is listed in Table 1.

Table 1.19 of the largest international IGS suppliers.

\begin{tabular}{|l|l|}
\hline Adotta & Jeb International \\
\hline Avanti & KI, Maars \\
\hline Cleastra & Maispace \\
\hline Della Valentina & Mdernus \\
\hline
\end{tabular}




\begin{tabular}{|l|l|}
\hline dHive & Muraflex \\
\hline Fantoni & Nello Wall Systems \\
\hline Faram & Steel Case \\
\hline Haworth & Studio Tag, and \\
\hline Infinium & Teknion. \\
\hline Inscape & \\
\hline
\end{tabular}

Although these suppliers offer a varying degree of product types in the IGS domain this research focused on fixed interior glazed partitions and moveable interior glazed partitions (Fig. 1). Data was collected by contacting the sales department and referring to the website of each supplier. For each supplier, a list of product lines was developed. For example, Studio Tag offers Tagwall Encore, Tagwall Encore Slimline, Tagwall Industrial Sash, Tagwall Ion, and Verde. Each product line was broken down into specific products offered. For example, Tagwall Ion comes in both single and double-glazed variants. Basic specifications, such as glass type, thickness, frame options, height restrictions, finish options, and more were noted and all of this data was recorded in a spreadsheet and is available by request.
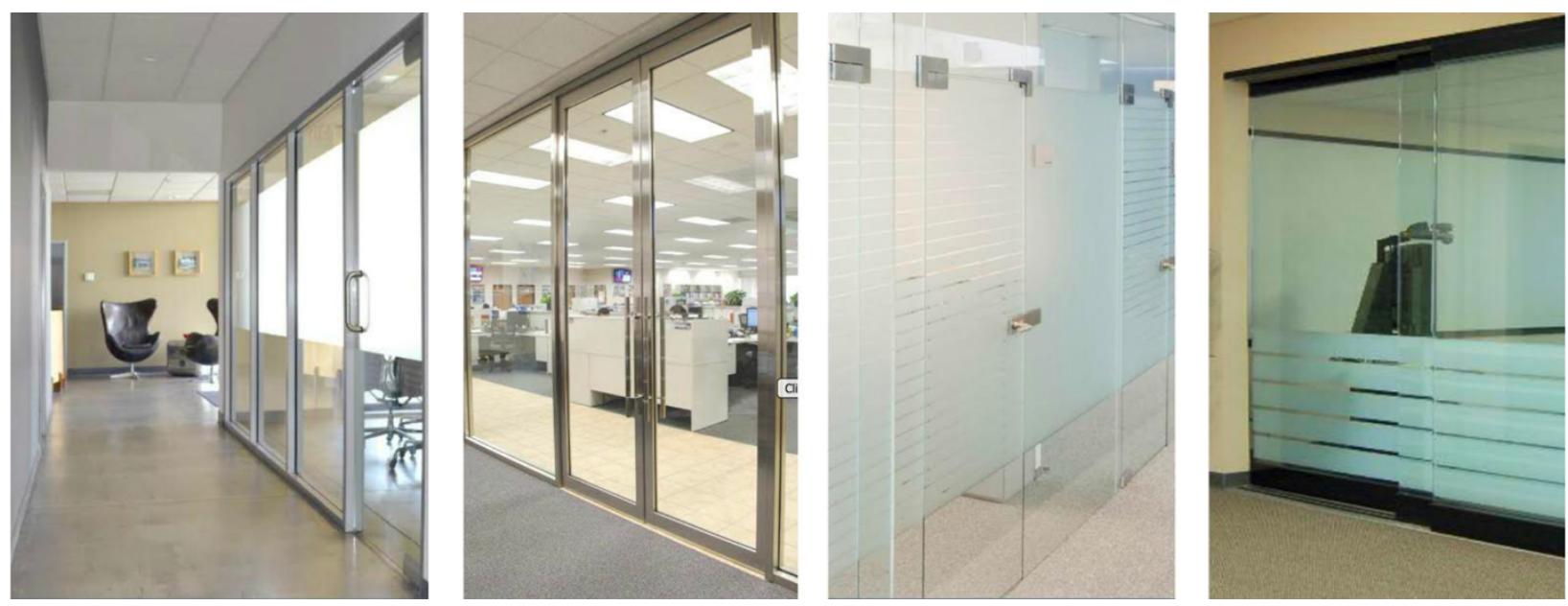

Figure 1. Interior glazed systems including framed and frameless partitions and doors.

\section{Phase 2 - Quantitative}

The second phase was to create and disseminate a questionnaire to design professionals across North America. The intent of the survey was to understand the circumstances in which IGS are being specified, and the roles of the designer, supplier, owner, and installer as it pertains to the selection and specification of the IGS in a project. A ten-question survey was developed.

Finding contact information for recipients of the survey involved leveraging the licensing bodies in each US state who have records of licensed architects and interior designers in their respective jurisdiction. Several states were able to assist and a list of over 23,000 architects and interior designers practicing in all 50 states was compiled. The survey was developed in SurveyMonkey and sent to the professionals on the list. It was available for a period of four weeks in which 485 respondents answered. The results were compiled and analyzed for trends. 


\section{Phase 3 - Qualitative}

In Phase 3 it was determined that qualitative information could be obtained from more in-depth interviews with design professionals than the survey afforded. Several designers indicated at the end of the survey that they would be willing to participate in a phone interview wherein a case study would be created concerning one of their projects. The goal was to interview the architect, as well as the owner, facilities manager, or users of the space to understand the involvement of each player in the design and specification of the interior glazing systems. Four case studies were ultimately performed for projects located in the states of Utah and Colorado respectively.

\section{RESULTS}

\section{Phase 1 - Archival}

The accounting of current products being offered showed the range of product types available from many of the major IGS suppliers. Many of the products available from the different suppliers are virtually indistinguishable from each other. For example, the frameless designs that are popular today are seemingly identical. Some differ by having visible top and bottom mullions without verticals, while others hide the top and bottom supports in the floor or ceiling details, creating a true 'frameless' design. Other than this small feature, there is nothing about the physical system that is different.

The more traditional interior storefront (framed) type systems appear fairly similar as well. The principle differences in the different products were the size of the mullion profiles and their available finish options. Many suppliers offer multiple sizes of mullions depending on the desired aesthetic of the space.

A few unique products exist on the market outside of the framed and frameless lines including:

- Studio Tag makes a wood veneered mullion system that looks like custom architectural millwork, for a much lower price.

- A few suppliers offer systems that integrate power and data cables into the mullions.

- Clestra offers a modular system that affords replacement options for the glass panels such as metal, wood, or textiles in areas that might benefit from less transparency in certain locations.

- Fantoni Group provides a sleek turn-key glazed acoustical room that offers sound privacy for small meetings in an open floor plan.

- Maars offers smart walls that can integrate touch screen displays into them.

- Finally, several suppliers offer smart glass that can change from transparent to opaque at the flip of a switch.

More examples can be found in the product spreadsheet on request. 


\section{Phase 2 - Quantitative}

Ultimately 485 licensed professionals responded to the survey. Table 2 shows the location of the respondents: approximately $70 \%$ of U.S. states were represented in the survey responses, with California, Florida, New York, Ohio, and Washington being more heavily represented. See Figure 2 for a breakdown of the size of the firms that the respondents currently belong to.

Table 2. Questionnaire respondents by state.

\begin{tabular}{|l|l|l|l|l|l|}
\hline Alabama & 0 & Maryland & 2 & Pennsylvania & 10 \\
\hline Alaska & 0 & Massachusetts & 6 & Rhode Island & 4 \\
\hline Arkansas & 2 & Michigan & 10 & South Carolina & 2 \\
\hline Arizona & 4 & Minnesota & 4 & South Dakota & 0 \\
\hline California & 28 & Mississippi & 2 & Tennessee & 4 \\
\hline Colorado & 4 & Missouri & 6 & Texas & 16 \\
\hline Connecticut & 2 & Montana & 0 & Utah & 4 \\
\hline Delaware & 0 & Nebraska & 0 & Vermont & 0 \\
\hline Florida & 72 & Nevada & 0 & Virginia & 2 \\
\hline Georgia & 14 & New Hampshire & 2 & Washington & 32 \\
\hline Hawaii & 2 & New Jersey & 4 & West Virginia & 0 \\
\hline Idaho & 0 & New Mexico & 4 & Wisconsin & 0 \\
\hline Illinois & 16 & New York & 38 & Wyoming & 0 \\
\hline Indiana & 12 & North Carolina & 4 & Washington DC & 77 \\
\hline Iowa & 0 & North Dakota & 4 & Unknown & \\
\hline Kansas & 4 & Ohio & 58 & & \\
\hline Kentucky & 4 & Oklahoma & 2 & & \\
\hline Louisiana & 0 & Oregon & 6 & & \\
\hline Maine & 0 & & & & \\
\hline
\end{tabular}

\section{What is the size of your firm?}

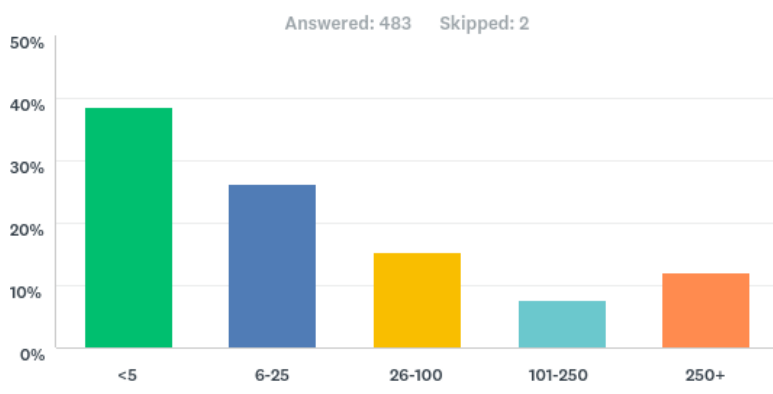

Figure 2. Firm sizes of the survey respondents. 


\section{Questionnaire Results Summary}

The purpose of the questionnaire was to understand how often architects are involved in projects that include interior glazing systems. It was determined that it would be useful to break down IGS into three categories for this question, so as to be able to understand not only how often IGS is used in their projects, but also which types of IGS are being used. The three categories of questioning include glass partitions, glass railings, and glass doors (Fig. 3).

\section{On what percentage of your interior projects do you specify IGS?}

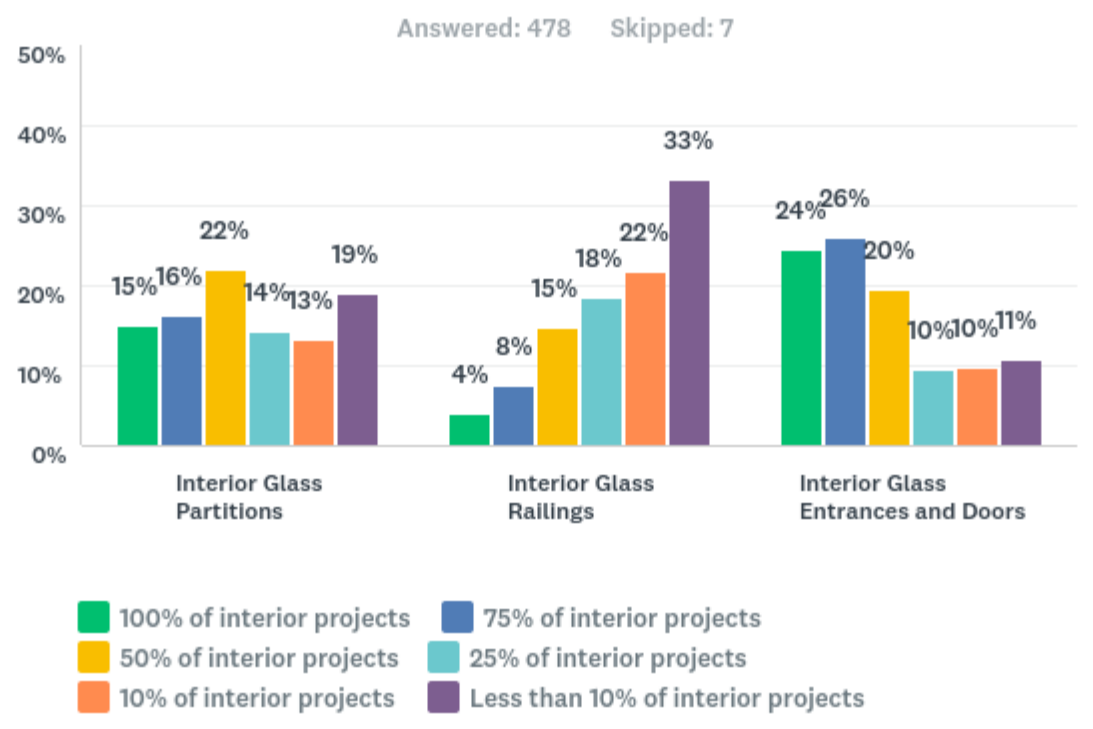

Figure 3. The frequency at which architects specify IGS for all projects.

As illustrated in Figure 3, interior glass doors are very commonly used, with about 50\% of respondents reporting that they use them in $75 \%$ or more of their projects. Compare that to glass partitions and glass railings, where only $30 \%$ and $12 \%$ of respondents report using them on $75 \%$ or more of the projects, respectively.

The next question of significance pertains to which project types they tend to specify IGS. This helps to determine if certain project types are more prone to include IGS. As can be seen in Figure 4 , the spread is not significant large, with only offices and retail trending to include more IGS than other building types. 


\section{Q3 How often do you specify IGS for the following building types?}

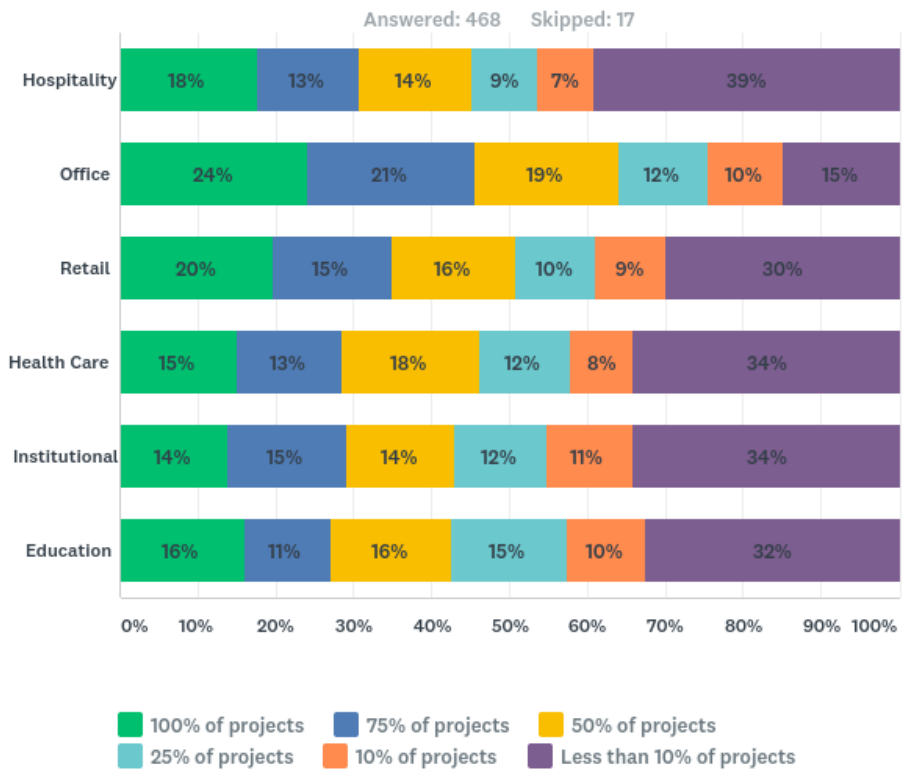

Figure 4. The distribution of the percentage of projects including IGS according to building type.

The next area of interest is the criteria by which IGS is selected for a project. Figure 5 shows the importance that designers place on the different aspects of glass when choosing it for a project. The most important criteria, according to those surveyed are aesthetics, visibility, client demand, and freedom of design.

Another important aspect of understanding how to successfully enter the interior glazing market is to know how designers prefer to learn about new systems. They are more likely to take the time to learn about a product if they are receiving the information by their preferred means of training. Figure 5 shows how the surveyed designers currently learn about IGS systems as well as how they would prefer to learn about them. Most of the designers prefer to learn about IGS through 'lunch and learns,' wherein representatives of the supplier will typically bring lunch to their office and give them a 30-60 minute presentation about their products, allowing them to see the products and ask questions (Fig.6). Designers also prefer to research IGS on their own, via the internet. 
Rate the importance of the criteria by which you select/specify IGS:

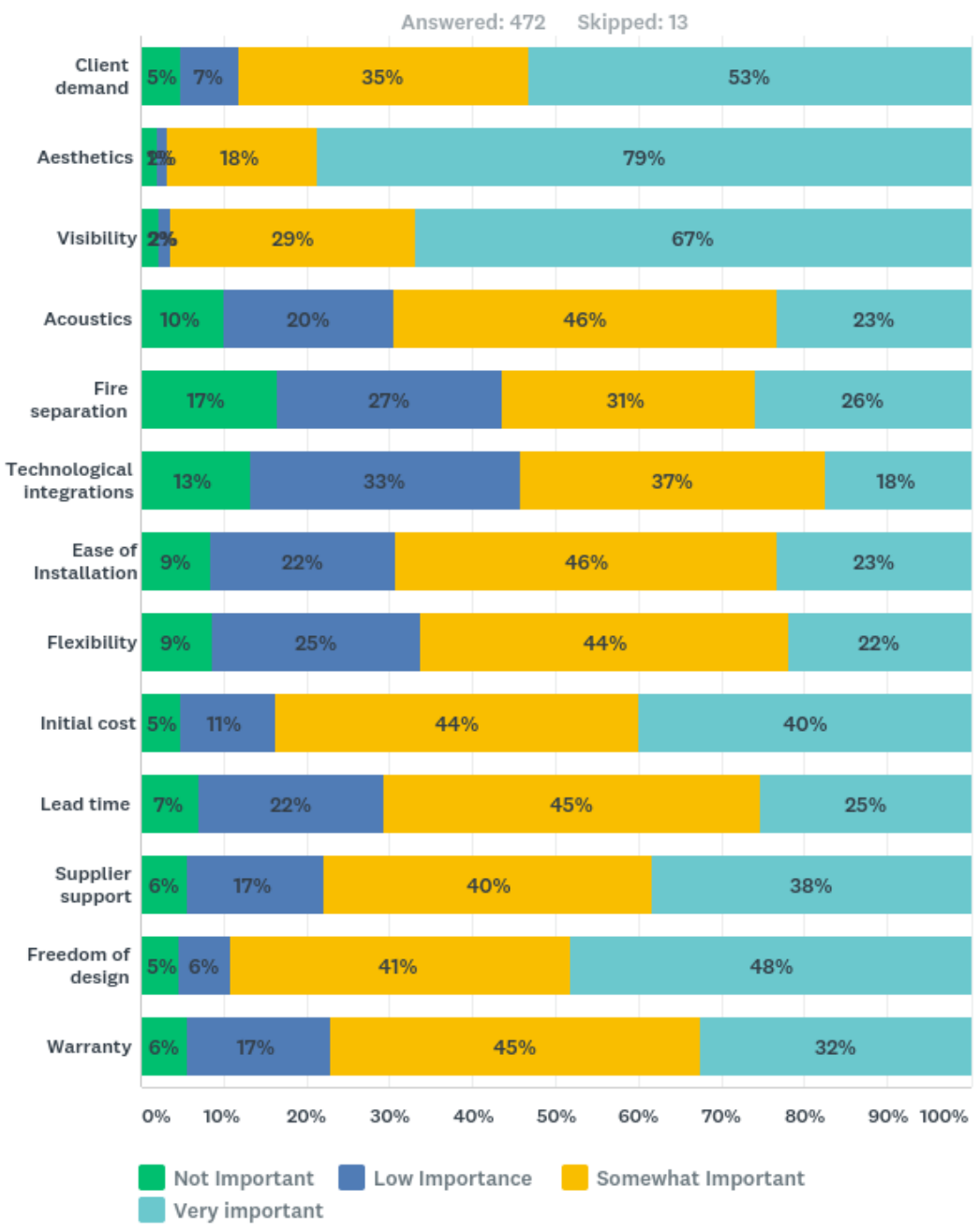

Figure 5. The importance of various criteria in architect selecting and specifying IGS.

How do you currently learn about IGS and how to you prefer to learn about IGS?

(Select all that apply)

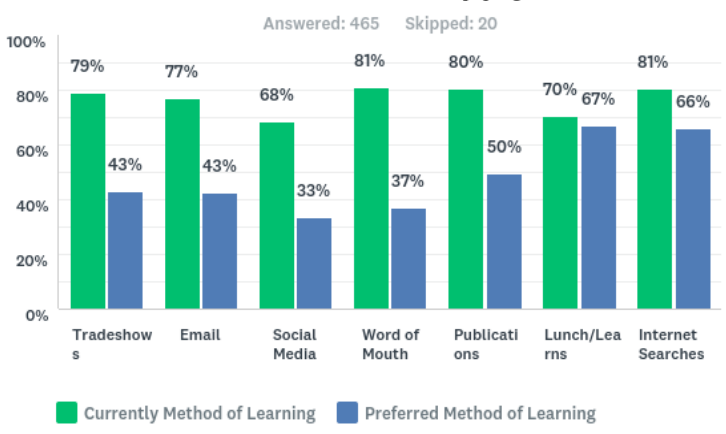

Figure 6. Methods by which architects learn about IGS. 


\section{Phase 3 - Case Studies}

Case Study \#1 - Jon M. Huntsman Hall

Jon M. Huntsman Hall, located at Utah State University in Logan, Utah, is a 125,000 square foot building for the School of Business. It includes many different types of IGS, including railings, partitions, and doors. There were many factors that drove the selecting the manufacturer for the IGS systems, but cost and aesthetics ultimately played a large role. The design architects defined which areas were to be glazed, but the local architects of record selected the actual glass suppliers. The contractor and users played a very small role in the selection of the IGS, while the architect of record did most of the research and made the recommendations.

\section{Case Study \#2 - WSU Student Enrollment Center}

The Student Enrollment Center at Wright State University is a remodel of an existing building that serves as a 'front door' to campus. It includes large areas of glazing so as to bring more natural light into a dark and gloomy space. The university gave the architect full discretion to choose the IGS systems. The architect opted to design a bespoke glazing system using large sheets of glass and hardware from C.R. Lawrence. This allowed for a minimalist look with no visible frames. This approach is typical of this architect, and reports that it them more freedom to design the system exactly how they want, rather than choose from a limited number of options from the supplier.

\section{Case Study \#3 - Polaris Hall}

Polaris Hall, at the U.S. Air Force Academy in Colorado Springs, Colorado, is home to the Character and Leadership Development program. There are many interior spaces including meeting and study areas that use IGS. Being a government project, the architect couldn't specify a certain supplier for the IGS, so they needed to create a performance specification for open bid. After the bids were procured, Teknion, the low bidder, was selected for the majority of the IGS in the project.

\section{Case Study \#4 - Spencer Foxx Eccles Building}

The Spencer Foxx Eccles Building at the University of Utah in Salt Lake City houses the students, staff, and faculty of the School of Business. The project includes some unique IGS that front offices and classrooms. Looking for an elegant solution to glazing that is adjacent to the large public spaces, the owner decided to have a frameless system. However, due to seismic requirements, they couldn't have a plain butt-glazed system because it needed more support. The owner and architect ended up using a Herculite system, which uses glass, mullion-like supports behind panels for additional structural support. The architect, MHTN, specified the IGS to be used, based on their own research. 


\section{CONCLUSIONS}

\section{IGS Products}

Based on the data from Figure 2, it can be determined which product types should be a priority for entering the interior glazing market. $70 \%$ of respondents specify interior glass doors on at least $50 \%$ of their projects. This was verified in the case study interviews as owners often want visibility into spaces through the doors. Interior glass doors can be specified even in spaces that have traditional framed walls.

Among the three types of products discussed in the survey, the second most common product is interior glass partitions. 54\% of survey respondents use glass partitions in at least half of their projects. While not as significant as the glass doors, it is still a majority.

The specification of glass partitions in projects underscores the importance of having glass doors available as well. Among the glass suppliers studied, it is apparent that their glass doors are often an integral part of their glass partition systems, as you would almost never have a glass wall with a solid door, even though glass doors in solid walls are common. It would be important to offer door types that integrate well with the design of the glass partitions, as well as doors that work well aesthetically with solid framed walls.

Glass railings were reportedly specified by significantly fewer designers. Only $27 \%$ of those surveyed specify glass railings on at least half of their projects. While 1 in 4 is not to be ignored, it should be less of a priority than glass partitions and doors, because it is used less than half as often.

\section{IGS Building Type Targets}

As seen in Figure 3, all of the building types discussed use interior glass products on a large portion of their projects. However, the most common building type to use IGS are offices. 64\% of those surveyed say they specify IGS in at least half of their office projects, and nearly a quarter of them specify it in $100 \%$ of their office projects. While having products designed for use in many product types would be important, having products designed to work especially well in office situations would be a necessity.

Another important target market for IGS is retail. 51\% of respondents said they use IGS in at least half of their retail projects, and $20 \%$ said they use it in all of their retail projects. Similar to offices, retail is a market segment that cannot be ignored.

Of those surveyed $45 \%, 46 \%, 43 \%$, and $43 \%$ reportedly use interior glass in at least half of their Hospitality, Healthcare, Institutional, and Education projects, respectively. 


\section{Glass Properties}

As seen in Figure 4, the overwhelming majority of those surveyed place the highest level of importance of in selected IGS on the aesthetics of the system and its ability to provide visibility between spaces. $67 \%$ said visibility is very important and $29 \%$ said it is somewhat important, meaning a mere $4 \%$ rated it as low or no importance. $79 \%$ said aesthetics was very important in selecting IGS and $18 \%$ said it was somewhat important. This shows that for most designers, choosing interior glass systems is mostly about making the space aesthetically compelling and transparent.

Another important criterion in selecting IGS is freedom of design. Designers want systems that are flexible enough to not inhibit their designs. In some cases this may mean they want moveable partitions so the client can make changes to the space in the future. In other cases, it may simply mean they want to have a lot of options in terms of how the systems look and function.

Initial cost is a significant factor. $84 \%$ of survey respondents rated initial cost as 'somewhat' or 'very' important. Using glass partitions, for example, already increases the cost of a space substantially over traditional framed walls. Systems that cost a premium without adding any extra features are unlikely to be chosen for a project, as budgets are typically already tight. If a supplier wants to sell large quantities of their products, they need to either be competitive with prices or they need to offer a vastly superior product to justify the added costs.

One somewhat deceptive criterion shown in Figure 4 is that of client demand. $88 \%$ of those surveyed rated client demand as either 'somewhat' or 'very' important. This shows that a major influence on a designer to use interior glass on a project is from the client. During several interviews for the case studies, it was mentioned that clients want glass, and will specifically ask for it in many spaces. This can be for a variety of reasons, but the repeating themes seems to be for visibility between spaces, to bring more natural light into the space, and to give a more refined and contemporary look to a space. However, while client demand has a great impact on whether or not IGS is used on a project, it has very little impact on what specific systems are ultimately selected.

In every interview where client desire for glass was mentioned, it was clarified that the clients did not know or care enough about the specific systems used to be involved in the decision at all. The only times the clients tend to be involved in the selection of a specific system is if the cost is high enough that they need to get the client's approval in order to specify. In these cases, the designer needs to make the case to the client that the desired system offers something unique enough to be worth the extra cost.

Expanding Recognition and Awareness 
Designers can only specify they systems that they know about. An important part of making sales is making sure that those specifying your product are familiar with it. Figure 5 demonstrates how designers prefer to learn about products. There are two ways that are vastly more preferred than the rest. These two means will need to be leveraged in order to educate designers in the methods that they prefer most.

First, 'lunch and learn' events are important. Designers are often considering options for projects for a considerable amount of time. Visiting them in their workplace when they are in the middle of their projects gives them the opportunity to not only become familiar with your product and ask questions about it, but also see how the products can work well with their current or future projects.

Finally, having a strong online presence is important for manufacturers. Optimizing online presence for search engine queries will gain the attention of designers that specify IGS.

\section{REFERENCES}

\footnotetext{
' Google Scholar Search:

https://scholar.google.com/scholar?start=0\&q=interior+glazing + partition \&hl=en\&as sdt=0,45
}

ii Glasstec 2016. Glass in Interiors: creating a mood with the help of top functionalities. Professional Article No. 9. Messe Dusseldorf North America. http://www.mdna.com/glasstecp52 Accessed June 15, 2017.

iii Vardaman, W. Trending to the Interior. Glass Magazine. November 24, 2015.

https://glassmagazine.com/article/commercial/trending-interior-1514578 Accessed June 15, 2017.

iv Raths, D. Brining down the walls (literally) to foster classroom collaboration. The Journal. March 11, 2013. https://thejournal.com/articles/2013/03/05/bringing-down-walls-literally-to-foster-classroomcollaboration.aspx?=THE21 Accessed January 30, 2018.

Gisolfi, P. A Sense of Place. School of Planning and Management. August 1, 2015. https://webspm.com/Articles/2015/08/01/Transparency.aspx Accessed January 30, 2018

Butterfield, E. (1999). The Future of the Classroom: interview with William DeJong. Design Share, Minneapolis, MN. https://files.eric.ed.gov/fulltext/ED460591.pdf Accessed online January 31, 2018.

$\checkmark$ Ziff, M. The Role of Glass in Interior Architecture: aesthetics, community and privacy. The Journal of Aesthetic Education, Vol. 38:4 Winter 2004. Pp. 10-21. University of Illinois Press. 